\title{
Design of Voice System for Intelligent Public Transportation System
}

\author{
Yunting Wu, Weici Liu*, Jinxin Guo and Ruisheng Liang
}

Department of Electronic Information Engineering, Guangzhou College of Technology and Business, Foshan 528138, China

${ }^{*}$ Corresponding author

Keywords: Voice system, Intelligent, Public transportation system.

\begin{abstract}
In this paper, we design a voice system of intelligent public transportation system which is based on STC89C51 micro-controller and voice module of the ISD4004. The display is by LCD12864. The software is compiled and debugged in Keil software, verified in experimental board. Some useful conclusions are obtained.
\end{abstract}

\section{Introduction}

With the rapid development of economy and the acceleration of urbanization process, people's living standards have been improved, and the number of private cars has been increasing. Urban traffic has become increasingly congested. According to our country's urban road condition and the experience of other countries' traffic development, in order to solve these problems caused by traffic conditions, we need to unswervingly carry out the "bus priority" policy.

The development of the global economy is greatly promoted by the rapid development of information technology. Every field in the world is trying to take the road of informatization, and transportation is no exception. Many countries begin to study intelligent public transport system. The emergence of intelligent public transport electronic stop signs has made the intelligent public transport system to a new stage of informationization. The application of intelligent bus voice system not only brings convenience to peoples who are not familiar with bus routes, but also avoids the trouble of staff reporting at every station, even prevents staff from misreporting and omission. [1-6].

Therefore, it has become a hot research topic that improve the public transport network, develop a more simple and intuitive, user-friendly and bus company's intelligent public transport voice system. It is of great significance to study and design a perfect voice system for intelligent public transport. The paper is structured as follows: starting from system model in section II, the The system structure and module design are introduced. In section III, the System tests are investigated and discussed. A brief conclusion is given in section IV.

\section{System Model}

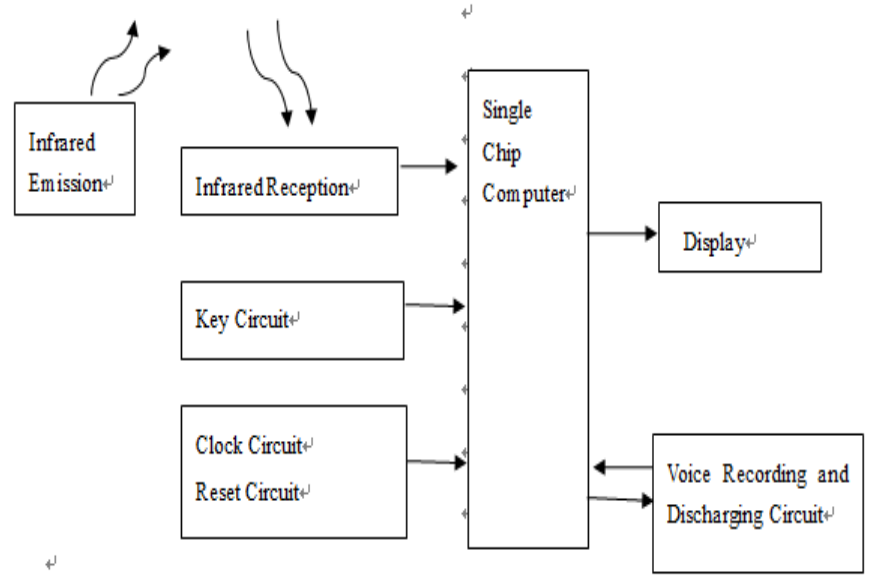

Figure 1. The system construction diagram 
The design of the system is about two major aspects: hardware and software. The modules include display part, voice module, main controller, key-press part and infrared module. The key module allows users to complete manual station announcement control. The main controller controls the display module to display the station information. The voice module is responsible for the voice station announcement. The infrared module makes the system complete automatic station announcement.

The system construction diagram is shown in Figure 1.

\section{Master Controller Scheme}

The single chip computer is one of the most important schemes for the system design. The STC89C51 processor is used in the system, which is designed to be manufactured in a highly integrated way with a long storage time. This processor can be operated with MCS-51 instructions and is universal in hardware interface. It has excellent performance in power consumption and low power consumption. The processor can run normally in many complex environments and has excellent stability. One of the most important points the cost of the processor is considerable and the price is very low. It can be seen everywhere in the electronic market.

\section{Voice Module Scheme}

ISD4004 series voice chips are mainly designed for recording and playback in this design. The ISD4004 series voice chips have 8-16 minutes recording and playback time, and the working voltage is $3 \mathrm{~V}$. It mainly adopts multi-level direct analog storage technology to achieve the goal of storing each sampling value directly in the flicker memory on the chip. Therefore, the sound reproduction is very natural and real. There is no murmur caused by quantization and compression of the recording circuit. The singlechip technology is used in the chip. Controller based on singlechip controls all operations, and the serial communication interface is used to send the operation commands.

\section{Infrared Module Scheme}

Infrared system is composed of transmitting and receiving. Emission is the responsibility of infrared light-emitting diodes, which emit infrared light. On the receiving side, we usually use photodiodes to receive infrared.

\section{Display Module Scheme}

The LCD12864 screen is used to connect the main control chip to display information, which can display not only Chinese characters, but also graphics. It has the remarkable characteristics of low power consumption and low voltage. Moreover, the LCD scheme is cheaper than the graphic lattice LCD scheme, and the circuit structure is relatively simple.

\section{Software Design}

The whole software development of this project includes the following contents: software initialization, key scan, voice broadcast, display, etc. The first time the device is opened, the parameters will be initialized. Then the system will scan the keys or receive infrared sensors to determine whether to broadcast voice. When infrared sensors are received or keys are pressed, the voice module will broadcast, and the LCD will display the station data. See Figure 2. 


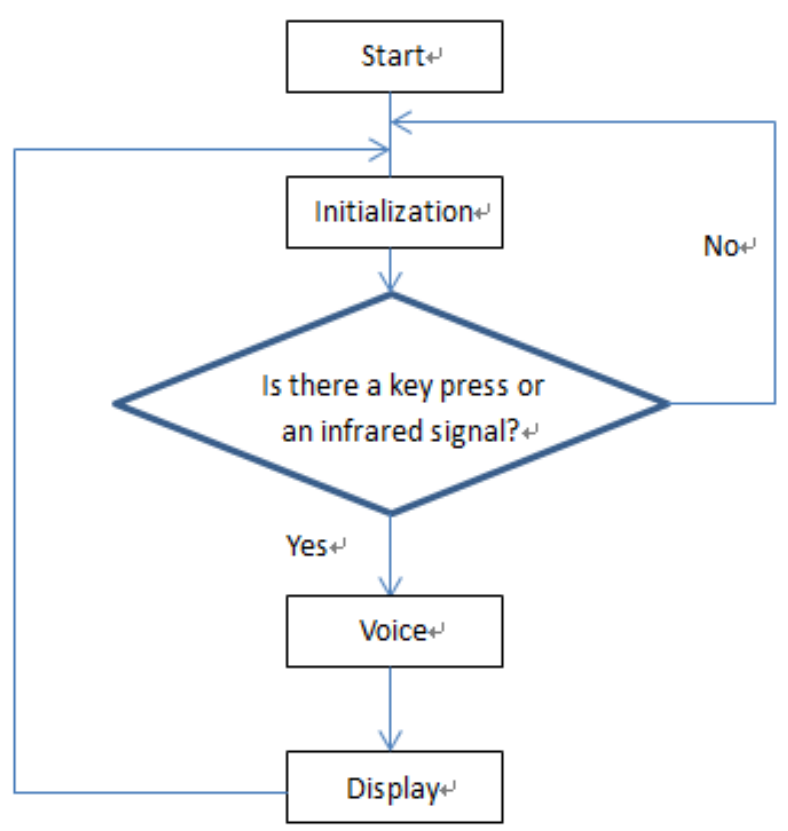

Figure 2. Software design chart

\section{System Test}

We debug it through the Keil tool which provides coding, translating, writing and debugging, and finally completing the debugging of the whole system.

In order to avoid short-circuit in welding process, the minimum system welding should be completed firstly, and the short-circuit detection should be carried out for each part of the functional circuit after welding.

(1) Press the recording key to record and play, and test whether the timbre meets the requirement. ISD4004 voice chip has the function of recording and playing. In order to achieve the natural and real effect of the played sound, multi-level direct analog storage technology is adopted.

(2) Connect the power supply, press the switch, the LCD will display the welcome words "Welcome to the bus" and arrive at the corresponding station, the display will display the corresponding station name, so that people can know the route in real time.

(3) Close the infrared transmitter to the infrared receiver to see if it can automatically report the station by infrared induction. When infrared induction is received, it is equivalent to press the key automatically, and the singlechip will control the voice chip to work well.

(4) Press the button to report the station. It should be ensured that each button can report the station and prevent misstatement and omission.

\section{Conclusion}

In summary, this design mainly realizes the voice system of intelligent public transport system based on single chip computer. The overall design scheme of voice system of intelligent public transport system is analyzed. The system structure design is completed. Then we determine the specific scheme of each function, clarify all design details and device selection. According to the connection relationship design software, software design is programmed by C language, and complete the development of each functional code, modular design, and finally combined together. Finally, the system is debugged to complete the system function.

\section{Acknowledgement}

This research was financially supported by 2019 Natural Science Project of Guangzhou College of Technology and Business (Grants No. KA201931), the Guangdong provincial College Students' innovation and entrepreneurship training program(No. 201813714013), and College Students' 
innovation and entrepreneurship training program of Guangzhou College of Technology and Business (No. xj201913714079).

\section{References}

[1] Oberli C, Torres-Torriti M , Landau D . Performance Evaluation of UHF RFID Technologies for Real-Time Passenger Recognition in Intelligent Public Transportation Systems[J]. IEEE Transactions on Intelligent Transportation Systems, 2010, 11(3):748-753.

[2] Heermann P D, Caskey D L . Intelligent Vehicle Highway System: Advanced Public Transportation Systems[J]. Mathematical and Computer Modelling, 1995, 22(4-7):445-453.

[3] Peng L, Ni Z , Xiao F . Design for Wireless Sensor Network-Based Intelligent Public Transportation System[C]// Proceedings of the 3rd international conference on Anti-Counterfeiting, security, and identification in communication. IEEE, 2009.

[4] Mulay S, Dhekne C , Bapat R , et al. Intelligent City Traffic Management and Public Transportation System[J]. Eprint Arxiv, 2013.

[5] Hua H. Application of TTS in Intelligent Bus Stop Announcement System for Public Transportation[J]. Process Automation Instrumentation, 2012.

[6] Jin-Xing H U, Yun-Cai L . Architecture and Key Technique of Intelligent Public Transportation Information Management System[J]. Communication and Transportati0n Systems Engineering and Information, 2005. 